\section{Case Reports in Ophthalmology}

Case Rep Ophthalmol 2018;9:102-107

This article is licensed under the Creative Commons Attribution-NonCommercial 4.0 International License (CC BY-NC) (http://www.karger.com/Services/OpenAccessLicense). Usage and distribution for commercial purposes requires written permission.

\title{
A Case of Fundus Oculi Albinoticus Diagnosed as Angelman Syndrome by Genetic Testing
}

\author{
Yurie Fukiyama ${ }^{a} \quad$ Masahiro Tonari $^{a}$ Junko Matsuo ${ }^{a}$ Hidehiro Oku ${ }^{a}$ \\ Jun Sugasawa ${ }^{a}$ Shuichi Shimakawa ${ }^{b}$ Tohru Ogihara ${ }^{c}$ \\ Nobuhiko Okamoto ${ }^{d}$ Tsunehiko Ikeda $^{a}$ \\ ${ }^{a}$ Department of Ophthalmology, Osaka Medical College, Takatsuki-City, Japan; \\ ${ }^{b}$ Department of Pediatrics, Osaka Medical College, Takatsuki-City, Japan; 'Department of \\ Neonatology, Osaka Medical College, Takatsuki-City, Japan; ${ }^{\mathrm{d}}$ Department of Medical \\ Genetics, Osaka Women's and Children's Hospital, Izumi-City, Japan
}

\section{Keywords}

Angelman syndrome - Fundus oculi albinoticus - Optic atrophy · Congenital anomaly .

Chromosome 15

\begin{abstract}
Purpose: To report a case of fundus oculi albinoticus diagnosed as Angelman syndrome (AS) via genetic testing. Case Report: This study reports on a 4-year-old boy. Since he had been having respiratory disturbance since birth, he underwent a complete physical examination to investigate the cause. The results indicated that he had various brain congenital abnormalities, such as a thin corpus callosum, as well as hydronephrosis, an atrial septal defect, and skin similar to patients with fundus oculi albinoticus. Examination revealed bilateral fundus oculi albinoticus, mild iridic hypopigmentation, optic atrophy, and poor visual tracking. Genetic testing revealed a deletion in the Prader-Willi syndrome/AS region on chromosome 15, and together with the results of methylation analysis, his condition was diagnosed as AS. Follow-up examinations revealed no change in the fundus oculi albinoticus and optic atrophy, nor did they indicate poor visual tracking. Conclusions: When fundus oculi albinoticus and optic atrophy are observed in patients with multiple malformations, AS should be considered as a differential diagnosis.




\section{Case Reports in Ophthalmology}

\begin{tabular}{l|l}
\hline DOI: 10.1159/000485964 & (c) 2018 The Author(s). Published by S. Karger AG, Basel
\end{tabular} www.karger.com/cop

Fukiyama et al.: A Case of Fundus Oculi Albinoticus Diagnosed as Angelman Syndrome by Genetic Testing

\section{Introduction}

Angelman syndrome (AS) is a complex teratogenic disorder characterized by severe developmental anomalies, convulsions, lateral curvature, easily induced laughing seizures, ataxic gait, and sleep disorder, etc. [1, 2]. AS is caused by a gene dysfunction on chromosome 15 , genetically derived from the person's mother, and it is regarded as a dysfunction resulting from the deletion or the mutation of the UBE3A gene copy [3]. The ophthalmic findings related to AS reportedly include fundus oculi albinoticus, poor visual tracking, eye movement abnormality, hyperopia, nystagmus, congestion failure, and aniridia, etc. [4-13].

Here, we report a case of fundus oculi albinoticus diagnosed as AS via genetic examination.

\section{Case Report}

This study reports on a 4-year-old boy who was born by vaginal delivery on August 7, 2013 (gestational age: 39 weeks; birth weight: 3,354 g; Apgar score: 3/10). Since he had been having respiratory disturbance since birth, oxygen therapy was administered. In addition, he had a swallowing disorder, etc. He underwent a complete physical examination after his admission to the Neonatal Intensive Care Unit at Osaka Medical College Hospital, Takatsuki-City, Japan, to investigate the causes of his condition. In regard to brain abnormalities, magnetic resonance imaging (MRI) of the boy's head revealed a thin corpus callosum, fissile brain disease, and polymicrogyria (Fig. 1a). Examination by MR urography revealed prominent ureteral dilation and hydronephrosis, and stenosis was observed at both the left and right ureteral inlets (Fig. 1b). In addition, atrial septal defects and milky skin were observed. Dandy-Walker syndrome was considered as a distinguishing malformation syndrome from the brain MRI findings, yet no definitive diagnosis was made. Thus, he was referred to the Department of Medical Genetics at Osaka Women's and Children's Hospital, Izumi-City, Japan. Upon examination, genetic testing results indicated a deletion of the Prader-Willi syndrome/AS (PWS/AS) areas. In combination with the results of methylation analysis, the diagnosis of AS was ultimately reached.

At 1 month after birth, the boy was referred to the Department of Ophthalmology, Osaka Medical College. Upon examination, no pupillary discrepancies in either eye and no obvious relative afferent pupillary defects were observed; however, the direct light reflection almost disappeared, and no visual response was observed. In regard to anterior ocular segment findings, the cornea was clear but slight hypopigmentation was observed in the iris (Fig. 2a, b). No abnormalities were found in the crystalline lens. In regard to fundus examination findings, hypopigmentation of the retinal pigment epithelium and the choroid and optic atrophy were observed in both eyes (Fig. 3a, b). Although he had been followed up periodically, no significant ophthalmic changes were detected in both optic atrophy and fundus oculi albinoticus with the development of his eyeballs. Now at 4 years old, both eyes have no light reflex and no visual responses, such as visual tracking.

\section{Discussion}

AS is a complex disease characterized by disorders, such as severe mental retardation, epilepsy, ataxic dyskinesia, and easily stimulated laughter $[1,2]$, and it reportedly occurs at a 


\section{Case Reports in Ophthalmology}

Case Rep Ophthalmol 2018;9:102-107

DOI: $10.1159 / 000485964$

(C) 2018 The Author(s). Published by S. Karger AG, Basel www.karger.com/cop

Fukiyama et al.: A Case of Fundus Oculi Albinoticus Diagnosed as Angelman Syndrome by Genetic Testing

frequency of 1 in every 15,000 births [2]. It is caused by the loss of function of the imprinted gene $U B E 3 A$, located on chromosome $15 \mathrm{q} 11-\mathrm{q} 13$, most cases reportedly being due to a mutation [3], and the risk of recurrence in the next generation is considered to be extremely low. PWS also occurs due to a similar deletion on chromosome 15, but the deletion on the chromosome in PWS cases is derived from the father, while the deletion on the chromosome in AS cases is derived from the mother, so it is a different disease [3].

In AS cases, the clinical findings include the facial expression, referred to as "happy puppet" (i.e., smiling puppet), severe delay in mental development with no ability to speak, a small head, the action of hitting both hands, muscle tension decrease, seizure attacks, and/or laughing attacks (i.e., laughing for no reason) [2]. In cases of chromosomal deletion, white skin, mandibular protrusion, popping out of the tongue, a head that is flat at the back, and sleep disturbance, etc., may be observed.

Genetic testing is essential for the diagnosis of AS. The chromosome fluorescent in situ hybridization method using a DNA probe is useful for detecting chromosomal deletion, which occurs in $70 \%$ of all AS patients. Since this deletion cannot be detected by ordinary chromosome analysis, the combined use of methylation testing is considered useful. In light of the diagnostic criteria reported by Williams et al. [14], electroencephalogram examination is also considered effective for the diagnosis of AS.

In regard to the ophthalmic complications associated with AS, fundus oculi albinoticus, poor visual tracking, abnormal eye movements, hyperopia, nystagmus, congestion failure, and aniridia, etc., have been reported [4-13]. Michieletto et al. [4] examined such complications in 34 AS patients and found a refractive error in $97 \%$ of their patients, strabismus in $75 \%$, and depigmentation in 53\%. In their study on AS patients, Dickinson et al. [5] reported low pigmentation of the choroid and iris in $70 \%$ of their patients and optic atrophy in over $40 \%$. Optical coherence tomography imaging appeared to be a useful examination to detect the morphological abnormalities, such as disc cupping, decreased retinal thickness, and abnormal macular contour. However, the patient in this study was bedridden, thus making optical coherence tomography imaging difficult to perform.

Even though the iris pigment in our patient was somewhat light, based on the fact that fundus examination clearly revealed fundus oculi albinoticus and that optic atrophy and poor visual tracking had also been observed, the findings in this case are consistent with those of previous reports on the ophthalmic findings in AS patients. However, our case differs from those of previous reports due to the merger of numerous brain congenital malformations, such as a thin corpus callosum, fissile brain disease, and polymicrogyria. The relationship between these abnormalities and AS is unknown, and it is highly possible that other genetic abnormalities may be involved. However, there have been reports on cases with genetic abnormality in the PWS/AS area, where the thin corpus callosum was merged [15], so this case could be related in some way.

In conclusion, the findings in this case of optic atrophy, hypopigmentation of the fundus and iris, and poor visual tracking suggest a poor prognosis of visual function. Our experience with this case has led us to believe that in patients in whom fundus oculi albinoticus and optic atrophy are observed together with multiple malformations, it is necessary to consider $\mathrm{AS}$ as a differential diagnosis.

\section{Acknowledgements}

The authors wish to thank John Bush for editing the manuscript. 
Fukiyama et al.: A Case of Fundus Oculi Albinoticus Diagnosed as Angelman Syndrome by Genetic Testing

Statement of Ethics

This case study was approved by the Ethics Committee of Osaka Medical College.

\section{Disclosure Statement}

There are no conflicts of interest to report for all authors.

\section{References}

1 Angelman H: Syndrome of coloboma with multiple congenital abnormalities in infancy. Br Med J 1961;1:1212-1214.

2 Laan LA, v Haeringen A, Brouwer OF: Angelman syndrome: a review of clinical and genetic aspects. Clin Neurol Neurosurg 1999;101:161-170.

-3 Dittrich B, Robinson WP, Knoblauch H, Buiting K, Schmidt K, Gillessen-Kaesbach G, Horsthemke B: Molecular diagnosis of the Prader-Willi and Angelman syndromes by detection of parent-of-origin specific DNA methylation in 15q11-13. Hum Genet 1992;90:313-315.

4 Michieletto P, Bonanni P, Pensiero S: Ophthalmic findings in Angelman syndrome. J AAPOS 2011;15:158-161.

-5 Dickinson AJ, Fielder AR, Young ID, Duckett DP: Ocular findings in Angelman's (happy puppet) syndrome. Ophthalmic Paediatr Genet 1990;11:1-6.

6 Clayton-Smith J: Clinical research on Angelman syndrome in the United Kingdom: observations on 82 affected individuals. Am J Med Genet 1993;46:12-15.

7 Rufa A, Dotti MT, Orrico A, Battisti C, Carletto F, Federico A: Retinochoroidal atrophy in two adult patients with Angelman syndrome. Am J Med Genet A 2003;122A:155-158.

8 Fridman C, Hosomi N, Varela MC, Souza AH, Fukai K, Koiffmann CP: Angelman syndrome associated with oculocutaneous albinism due to an intragenic deletion of the P gene. Am J Med Genet A 2003;119A:180-183.

-9 King RA, Wiesner GL, Townsend D, White JG: Hypopigmentation in Angelman syndrome. Am J Med Genet 1993;46:40-44.

10 Fryburg JS, Breg WR, Lindgren V: Diagnosis of Angelman syndrome in infants. Am J Med Genet 1991;38:58-64.

11 Low D, Chen KS: UBE3A regulates MC1R expression: a link to hypopigmentation in Angelman syndrome. Pigment Cell Melanoma Res 2011;24:944-952.

$\$ 12$ Adams D, Horsler K, Mount R, Oliver C: Brief Report: A longitudinal study of excessive smiling and laughing in children with Angelman syndrome. J Autism Dev Disord 2015;45:2624-2627.

-13 Mount R, Oliver C, Berg K, Horsler K: Effects of adult familiarity on social behaviours in Angelman syndrome. J Intellect Disabil Res 2011;55:339-350.

-14 Williams CA, Angelman H, Clayton-Smith J, Driscoll DJ, Hendrickson JE, Knoll JH, Magenis RE, Schinzel A, Wagstaff J, Whidden EM, Zori RT: Angelman syndrome: consensus for diagnostic criteria. Am J Med Genet 1995;56:237-238.

15 Mohandas TK, Park JP, Spellman RA, Filiano JJ, Mamourian AC, Hawk AB, Belloni DR, Noll WW, Moeschler JB: Paternally derived de novo interstitial duplication of proximal $15 q$ in a patient with developmental delay. Am J Med Genet 1999;82:294-300. 


\section{Case Reports in Ophthalmology}

\begin{tabular}{l|l}
\hline Case Rep Ophthalmol 2018;9:102-107 \\
\hline DOI: 10.1159/000485964 & $\begin{array}{l}\text { @ 2018 The Author(s). Published by S. Karger AG, Basel } \\
\text { www.karger.com/cop }\end{array}$ \\
\hline
\end{tabular}

Fukiyama et al.: A Case of Fundus Oculi Albinoticus Diagnosed as Angelman Syndrome by Genetic Testing

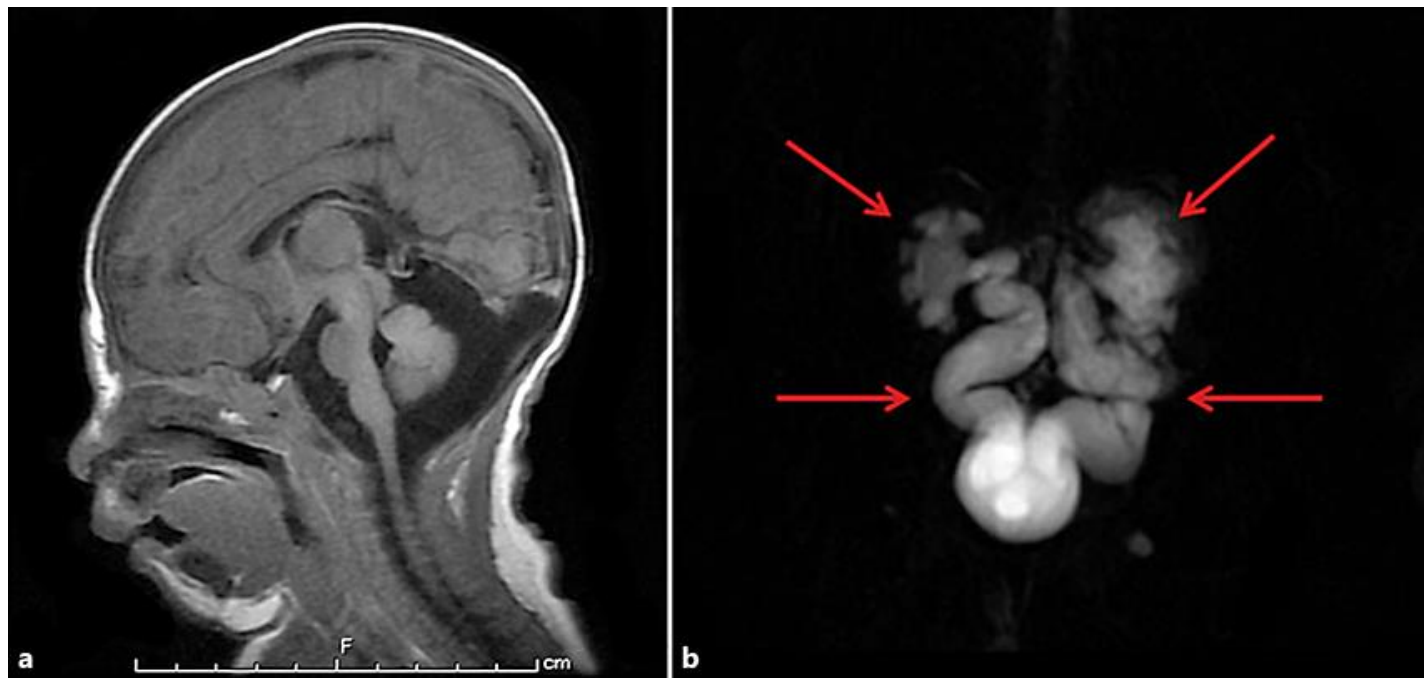

Fig. 1. Magnetic resonance image (MRI) of the patient's head and MR urography. a MRI of the head revealed a thin corpus callosum, fissile brain disease, and polymicrogyria. b MR urography revealed hydronephrosis.

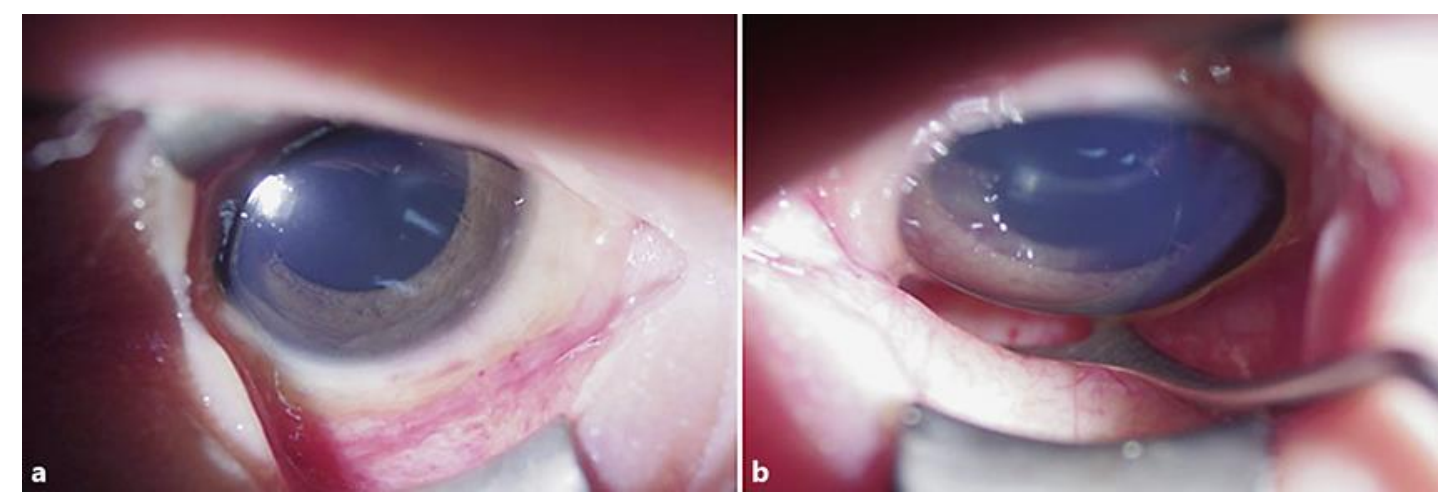

Fig. 2. Anterior segment photograph obtained 1 month after birth (a right eye, b left eye). Slight hypopigmentation was observed in the iris in both eyes. 
Case Reports in
Ophthalmology

Case Rep Ophthalmol 2018;9:102-107

DOI: $10.1159 / 000485964$

C 2018 The Author(s). Published by S. Karger AG, Basel www.karger.com/cop

Fukiyama et al.: A Case of Fundus Oculi Albinoticus Diagnosed as Angelman Syndrome by Genetic Testing

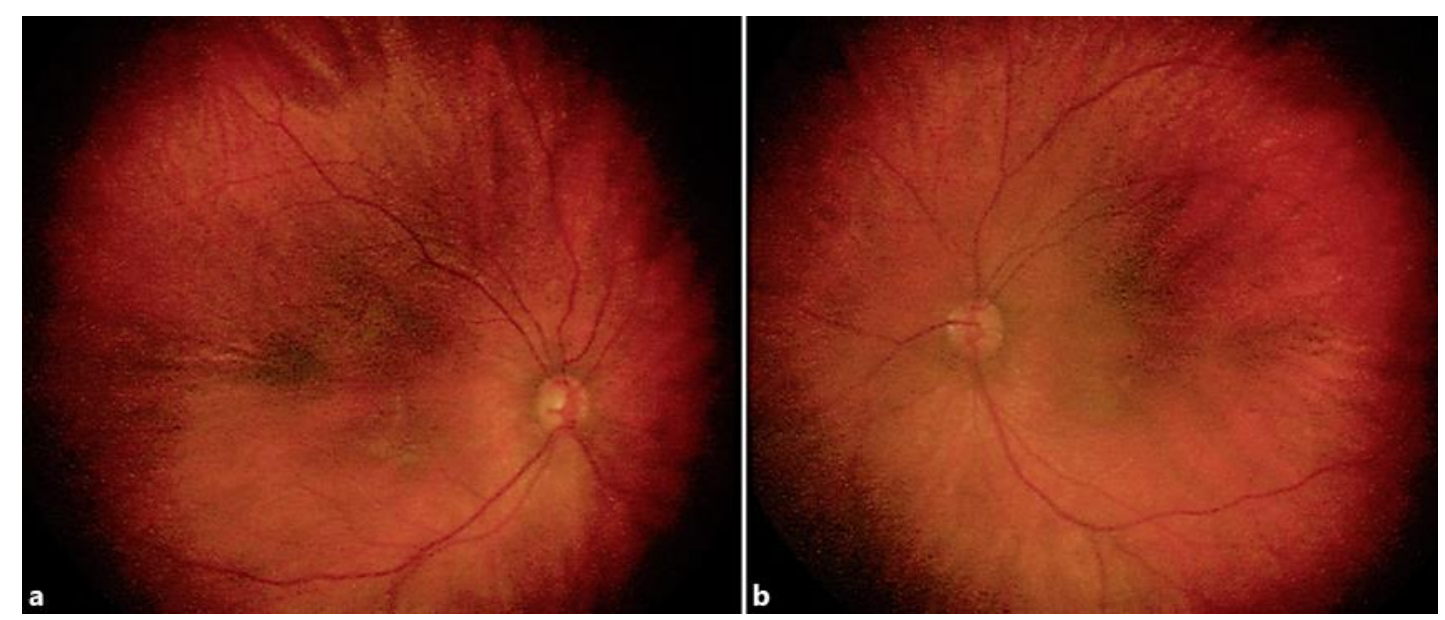

Fig. 3. Fundus photograph obtained 1 month after birth (a right eye, b left eye). Hypopigmentation of the retinal pigment epithelium and the choroid and optic atrophy were observed in both eyes. 